\title{
Presence of additional Plasmodium vivax malaria in Duffy negative individuals from Southwestern Nigeria
}

Mary Aigbiremo Oboh ${ }^{*}$ (1) , Upasana Shyamsunder Singh ${ }^{2,3}$, Daouda Ndiaye ${ }^{4}$, Aida Sadikh Badiane ${ }^{4}$, Nazia Anwar Ali ${ }^{5}$, Praveen Kumar Bharti ${ }^{5}$ and Aparup Das ${ }^{3^{*}}$

\begin{abstract}
Background: Malaria in sub-Saharan Africa (SSA) is thought to be mostly caused by Plasmodium falciparum. Recently, growing reports of cases due to Plasmodium ovale, Plasmodium malariae, and Plasmodium vivax have been increasingly observed to play a role in malaria epidemiology in SSA. This in fact is due to the usage of very sensitive diagnostic tools (e.g. PCR), which have highlighted the underestimation of non-falciparum malaria in this sub-region. Plasmodium vivax was historically thought to be absent in sSA due to the high prevalence of the Duffy negativity in individuals residing in this sub-continent. Recent studies reporting detection of vivax malaria in Duffy-negative individuals from Mali, Mauritania, Cameroon challenge this notion.
\end{abstract}

Methods: Following previous report of P. vivax in Duffy-negative individuals in Nigeria, samples were further collected and assessed RDT and/or microscopy. Thereafter, malaria positive samples were subjected to conventional PCR method and DNA sequencing to confirm both single/mixed infections as well as the Duffy status of the individuals.

Results: Amplification of Plasmodium gDNA was successful in 59.9\% (145/242) of the evaluated isolates and as expected $P$. falciparum was the most predominant (91.7\%) species identified. Interestingly, four $P$. vivax isolates were identified either as single (3) or mixed (one P. falciparum/P. vivax) infection. Sequencing results confirmed all vivax isolates as truly vivax malaria and the patient were of Duffy-negative genotype.

Conclusion: Identification of additional vivax isolates among Duffy-negative individuals from Nigeria, substantiate the expanding body of evidence on the ability of P. vivax to infect RBCs that do not express the DARC gene. Hence, such genetic-epidemiological study should be conducted at the country level in order to evaluate the true burden of P. vivax in Nigeria.

Keywords: Sub-Saharan Africa, Duffy Antigen Receptor for Chemokines, Plasmodium vivax, Mix-infection, Geneticepidemiology

*Correspondence: moboh@mrc.gm; aigbi4god@gmail.com; aparupdas@nirth.res.in

${ }^{1}$ Medical Research Council Unit The Gambia at LSHTM, Fajara, P.O. Box 273, Banjul, Gambia

${ }^{3}$ Genomic Epidemiology Laboratory, Division of Vector Borne Diseases, ICMR-National Institute of Research in Tribal Health, Jabalpur, India Full list of author information is available at the end of the article

\section{Background}

Malaria is a critical infectious disease of public health importance that provokes considerable mortality in all endemic countries. The tremendous gains seen in cases and mortality reduction is as a result of deliberate intervention strategies [1]. However, the observed benefits have seen a plateau in the last 2 years especially in Africa, where, the greatest burden of disease is mostly

c) The Author(s) 2020. This article is licensed under a Creative Commons Attribution 4.0 International License, which permits use, sharing, adaptation, distribution and reproduction in any medium or format, as long as you give appropriate credit to the original author(s) and the source, provide a link to the Creative Commons licence, and indicate if changes were made. The images or other third party material in this article are included in the article's Creative Commons licence, unless indicated otherwise in a credit line to the material. If material is not included in the article's Creative Commons licence and your intended use is not permitted by statutory regulation or exceeds the permitted use, you will need to obtain permission directly from the copyright holder. To view a copy of this licence, visit http://creativeco mmons.org/licenses/by/4.0/. The Creative Commons Public Domain Dedication waiver (http://creativecommons.org/publicdomain/ zero/1.0/) applies to the data made available in this article, unless otherwise stated in a credit line to the data. 
impacted. In sub-Saharan Africa (sSA), the majority (99\%) of the malaria infections is thought to be due to Plasmodium falciparum and, rarely by Plasmodium ovale, Plasmodium malariae, while Plasmodium vivax is not even considered as one of the players [1] in shaping malaria epidemiology in sSA. With the availability of tools that are more sensitive, the detection of nonfalciparum and even vivax human malaria parasites has gained more attention in sSA [2-6].

Historically, P. vivax prevails in Asia, $[7,8]$, South America $[9,10]$ and has some scanty presence in the Horns of Africa, such as in Djibouti [11], Eritrea [12], Somalia [13, 14], Ethiopia [15-18] and Sudan [19, 20]. Thus, $P$. vivax has a much wider geographical distribution outside of Africa unlike falciparum malaria. Hence, the former notion that $P$. vivax originates from Asia and South America, then gradually finds its way into Africa through the trade-route corridor is being opposed by current evidences. These recent proofs support the hypothesis that, $P$. vivax could have originally evolved from a vivax-like strain detected in non-human primates in Africa [21, 22] and, from there dispersed to other continents during the period of human migration. Although, both hypotheses (whether from Africa to Asia or, Asia to Africa) require further validation. Notwithstanding that, it seems likely that there might be an interplay of both hypotheses, in which case, simultaneous occurrence and selective adaptation of the Duffy negative allele in sSA might have resulted in the absence of vivax malaria in the region. Nonetheless, later re-introduction of $P$. vivax into sSA might have happened when individuals expressing the Duffy null allele travels between continents and countries where $P$. vivax is endemic.

The Duffy (gp-FY; CD234) gene is the fourth red blood cell (RBC) gene after thalassemia, sickle cell anaemia and glucose-6-phosphate dehydrogenase (G6PD) associated with resistance to Plasmodium species [23] albeit with particular protection against vivax malaria. Also known as the Duffy antigen receptor for chemokines (DARC), it is a variable receptor usually expressed on the surface of the red blood cell (RBC) and employed by $P$. vivax merozoites in gaining access in the $\mathrm{RBCs}$ and establishing its erythrocytic infection [24]. DARC which is located on chromosome 1 has two exons and a single nucleotide substitution from a thymine $(\mathrm{T})$ to a cytosine (C) upstream of the promoter region that nullifies the expression on RBCs ultimately resulting in the $\mathrm{FYO}^{*}$ allele [25]. This $\mathrm{FYO}^{*}$ null allele predominates amongst sSA inhabitants as with African-Americans but, has a very sparse representation in individuals of other ancestry [26]. Thus, the FYO* null allele has been validated to confer protection against $P$. vivax infection
[23] in this sub-region. Nevertheless, 11 countries in this region (Oboh et al. unpublished) have reported the occurrence of $P$. vivax making it more real that vivax malaria might be gradually finding its way into sSA, and it can, therefore, be postulated that hidden transmission is occurring in this region. In some of these studies, such as in those conducted in Angola, Cameroon, Kenya, Madagascar, Mali and Mauritania, the Duffy status of the infected individuals was characterized and they were found to be mostly Duffy negative [3, 4, 27-30]. In others, however, the investigators were concerned with the identification of $P$. vivax without stating the Duffy status of the infected individuals [5,31-33]. Interestingly, all studies were carried out amongst indigenous individuals with little or no travel history to other vivax endemic areas. Therefore, the possibility of imported infection can be ruled out.

In Nigeria, $P$. falciparum is responsible for $>95 \%$ of malaria infection, with $P$. malariae and $P$. ovale contributing a meagre $<5 \%$ of infection $[1,34]$. Data implicating $P$. vivax infection in Nigeria include its detection in a visiting pregnant female [35] and, two cases detected by microscopy [36, 37], both of which were not confirmed by any molecular technique. Nevertheless, evidence from previous data molecularly (by PCR) confirmed [6] five Duffy negative individuals to be infected with $P$. vivax isolates from Nigeria. Interestingly, all the vivax malaria cases had been subsequently confirmed by capillary sequencing. Thus, as a follow-up to our previous study, samples were collected from two sites-Oredo and Kosofe in Edo and Lagos state and evaluated with the classical PCR method. In order to confirm these additional $P$. vivax isolates (both single and mixed infection), sequencing by Big Dye Terminator was done. In addition, the Duffy status of the individuals was determined. The importance of such genomic epidemiological studies cannot be underestimated in this era of malaria elimination, as attention also needs to be given to non-falciparum infection, if the ambitious, albeit achievable 2030 elimination goal is to be reached.

\section{Methods}

Ethical approval for this study was obtained from the Institutional review board of the Nigerian Institute of Medical Research and only consenting individuals were enrolled in the study.

Blood samples were purposefully collected from all symptomatic patients attending two hospitals in Lagos (Gbagada) and Edo (Central) states within the study duration (December 2016-January 2017). Patients were recruited if they are $\geq 2$ years and, do not have any severe medical conditions, while pregnant women and nursing mothers were excluded from the study. Samples were 
quickly subjected to malaria rapid diagnostic test kit, employing the manufacturer's instruction (Pf-HRPIICare Start ${ }^{\circledR}$, Access Bio Inc, Batch number M014L04M014M10) followed by microscopy by a World Health Organization (WHO) expert microscopist. Two dried blood-spots (DBS) per patient per filter paper (242 in total), irrespective of their status (positive or negative by any of the techniques above) were made on Whatmann ${ }^{\circledR}$ (GE Healthcare, Life Sciences) filter paper. All DBS were brought to the ICMR-National Institute of Research in Tribal Health (ICMR-NIRTH), Jabalpur, India, where all molecular including DNA sequencing work have been conducted.

Employing the Qiagen ${ }^{\circledR}$ Mini kit (the QIAamp DNA Blood Mini Kit; Hilden, Germany), genomic DNA was isolated from all 242 samples and subsequently subjected to nested PCR diagnostic protocol targeting the 18S rRNA to identify all four Plasmodium infecting species using primer pairs as designed earlier [38]. For each PCR run, a negative control (nuclease free water) and positive controls (sequenced confirmed Plasmodium species-for all four species) were added. In addition, a part of the promoter region of Duffy gene (for isolates that are $P$. vivax positive) was PCR amplified and sequenced in order to determine their Duffy status using protocols and primer sequence detailed in our previous work [6]. Representative isolates of Plasmodium species (P. falciparum, P. vivax, P. malariae and P. ovale) were purified (using Fast ${ }^{\mathrm{AP}}$ alkaline phosphatase and exonuclease I) and processed for sequencing by Sanger method (an in-house facility of ICMR-NIRTH, Jabalpur) in both direction (2X coverage). Sequencing was performed on the purified PCR products in a volume of $10 \mu \mathrm{l}$ with $0.5 \mu \mathrm{l}$ of Terminator ready reaction mix (TRR), $1.6 \mathrm{pmol}$ of gene specific primer and $5 \mathrm{X}$ reaction buffer with a cycling condition of $96{ }^{\circ} \mathrm{C}$ denaturation for $10 \mathrm{~s}$ (25 cycles), annealing at $50{ }^{\circ} \mathrm{C}$ for $5 \mathrm{~s}$ and an extension of $60{ }^{\circ} \mathrm{C}$ for 4 minutes. Base calling of nucleotide and chromatogram visualization was achieved using the sequence analysis software accompanying the DNA analyser (Sequence analyser ${ }^{\mathrm{TM}}$ ), while sequence alignment was carried out with BioEdit sequence alignment editor v.7.0.5.3. Contiguous sequences were aligned with their respective reference strains ( $P$. vivax-SAL-1 accession number U03079.1; $P$. falciparum-3D7 accession umber XR_002273095.1; P. ovale-accession number L48987.1; $P$. malariae-accession number NG_011626.30 and, the Duffy gene; accession number NG_011626.30). In addition, the positive predictive value, negative predictive value and Kappa's test statistics were determined for each diagnostic tool in order to evaluate their performance.

\section{Results}

Between December 2016 and January 2017, a total of two hundred and forty-two samples were collected from both study areas, with majority of the samples (171) being from Oredo in Edo State. The mean age group from both localities are almost the same, 25 years in Kosofe and 26 years in Oredo. As with the mean age, the ratio of male to female is almost same (1:1.2) (Table 1). All 242 samples were subjected to the three diagnostic tools (RDT, microscopy and PCR) and the outcome were widely different. While RDT (187) and PCR (145) gave the highest positive results, that of microscopy was abysmally poor detecting only 53 positive isolates. Thus, using PCR as the gold standard RDT gave a higher sensitivity (84.8\%), although with a low specificity (34\%). On the other hand, the specificity of microscopy was remarkably higher $(82.5 \%)$ than what was obtained by RDT.

A converse pattern was noticed with regards to the likelihood of a positive or negative sample being correctly identified as such. For RDT, the chances of a positive samples turning out positive by PCR-positive predictive value (PPV) was lower $(65.8 \%)$ than what was observed with microscopy $(67.9 \%)$ while the chances of it being picked as truly negative; negative predictive value (NPV) was high $(60 \%)$ (Table 2).

As expected, $P$. falciparum was the most abundant malaria species detected in both localities (106 in Oredo and 27 in Kosofe). The occurrence of other species in both states were rare either in single (one P. malariae, one $P$. ovale, three $P$. vivax) or mixed infections (six $P$. ovale/ $P$. falciparum, one P. falciparum/P. vivax -1) (Fig. 1). The gDNA of the identified $P$. vivax isolates were re-extracted and amplified twice following a protocol described earlier [6] in order to be sure of their status. Gel documentation of all newly identified isolates is presented in Fig. 2.

Surprisingly, all $P$. vivax isolates sequences showed perfect homology (100\% similarity) with their references (Fig. 3 for P. vivax).

\section{Table 1 Background information of the study participants}

\begin{tabular}{llll}
\hline & Kosofe & Oredo & Total \\
\hline Number & 71 & 171 & 242 \\
Percentage (\%) & 29.3 & 70.7 & 100 \\
Age (years) & & & \\
$\quad$ Mean & 25 & 26 & \\
Range & $2-85$ & $2-86$ & \\
Sex & & & 109 \\
Male & 36 & 73 & 133 \\
Female & 35 & 98 & \\
\hline
\end{tabular}


Table 2 Diagnostic performance of the different tools

\begin{tabular}{|c|c|c|c|c|c|c|c|c|c|}
\hline & & \multicolumn{2}{|l|}{ PCR } & \multirow[t]{2}{*}{ Sensitivity (\%) } & \multirow[t]{2}{*}{ Specificity (\%) } & \multirow[t]{2}{*}{ PPV (\%) } & \multirow[t]{2}{*}{ NPV (\%) } & \multirow[t]{2}{*}{ Kappa's test } & \multirow[t]{2}{*}{$P$ value } \\
\hline & & Positive & Negative & & & & & & \\
\hline \multicolumn{10}{|c|}{ Microscopy } \\
\hline & Positive & 36 & 17 & 24.8 & 82.5 & 67.9 & 42.3 & 0.063 & 0.18 \\
\hline & Negative & 109 & 80 & & & & & & \\
\hline \multicolumn{10}{|c|}{ RDT } \\
\hline & Positive & 123 & 64 & 84.8 & 34.0 & 65.8 & 60.0 & 0.203 & 0.01 \\
\hline & Negative & 22 & 33 & & & & & & \\
\hline
\end{tabular}

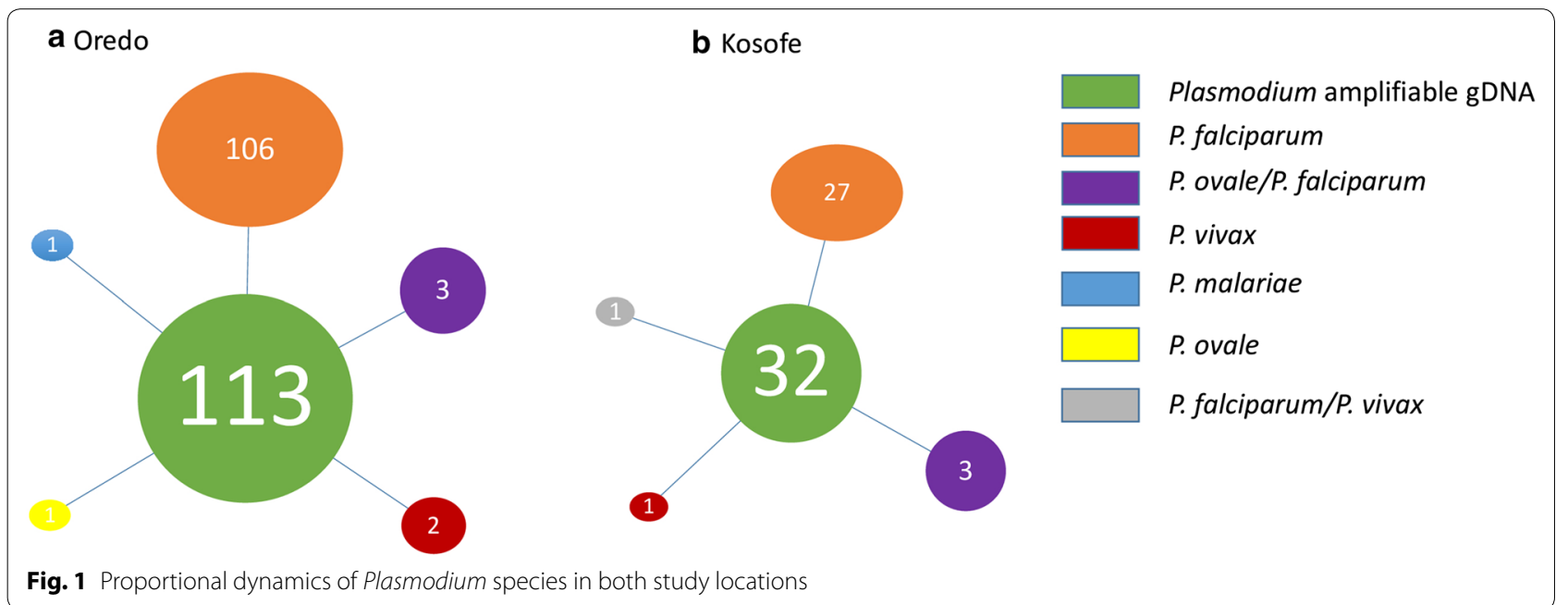

In order to discern the Duffy status of those P. vivax infected patients, a portion of the DARC gene (precisely the promoter region covering the T33C point mutation) was amplified and sequenced following previous protocol [39]. Unanticipatedly, all four patients infected with $P$. vivax carried a single cytosine $(C)$ peak at the 33rd nucleotide position upstream (Fig. 4), confirming that none of them expressed the Duffy gene on their RBCs and as such are Duffy negative.

\section{Discussion}

Plasmodium genomic DNA was amplifiable in more than half of the isolates. Non-amplification of other samples including those positive by microscopy could be due to a number of reasons from low parasite concentration, mutation in the annealing sites of the target gene to PCR technical inhibition. The identification of more $P$. vivax isolates among these Duffy-negative individuals from Nigeria substantiate the expanding body of evidence of the ability of $P$. vivax to infect RBCs that do not express the DARC gene. Although, a very recent finding points to another domain on the reticulocyte-transferring receptor 1 as a specific $P$. vivax receptor [40] on the reticulocyte.
This is being proposed to be an alternate route of entry by $P$. vivax into the RBCs, however, there is need for further verification. The above hypothesis is one of the proposition being made to support the observation of $P$. vivax in sSA [41]. Another which relies on the first conjecture (assuming it is agreed that $P$. vivax at least possesses alternative invasion pathway), is that the Duffy positive carriers in northern part of Africa and the Afro-Asiatic populations of Sudan, Somalia [20, 42] and Ethiopia [43, 44] serve as reservoir to effect transmission to Duffy negative individuals in those areas as well as other countries (in sSA) through migration. Albeit, this particular hypothesis at play here is yet to be determined. One thing is clear here, the true epidemiological situation of $P$. vivax in sSA in particular and Africa in general is yet to be ascertained.

The detection of additional vivax malaria is not unexpected as cases of $P$. vivax have been identified in many countries in sSA [3-5, 29, 33, 45-48] including Nigeria [6], where, it was thought to be absent due to the non-expression of the DARC gene on the RBC of majority of the population. Thus, this is adding to the 

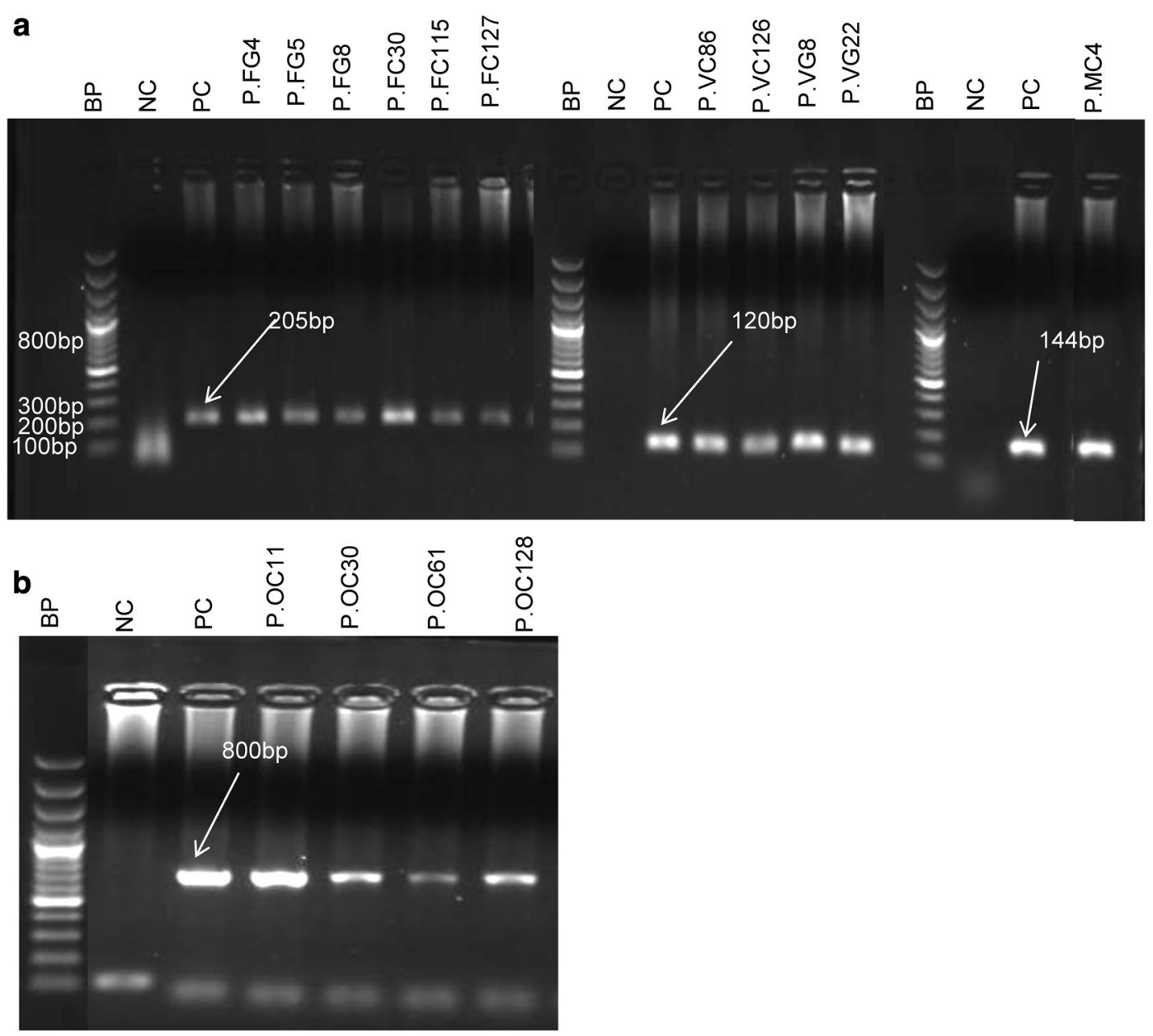

Fig. 2 Gel documentation of various Plasmodium species. a First well—DNA base pair ladder (100 bp), well 2: NC- negative control template (distill water), well 3- PC-P. falciparum positive control, well 4-9- isolates of P. falciparum, well 10- DNA base pair ladder, wells 11 and 12 - negative and positive controls of $P$. vivax, wells 13-16- $P$. vivax samples, well 17- DNA base pair ladder (100 bp), 18 and 19- negative and positive controls of $P$. malariae, well 20- the only additional P. malariae detected. b well 1- DNA base pair ladder (100 bp), wells 2 and 3 - negative and positive controls of $P$. ovale, wells 4-7- P. ovale isolates

Y Biodit Sequence Alignment Editor - [Untitled1]

F File Edit Sequence Alignment View Accessory Application RNA World Wide Web Options Window Help

B

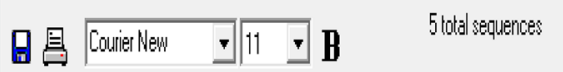

\begin{tabular}{|c|c|c|}
\hline Mode: Seled/silde & $\begin{array}{l}\text { Selection:0 } \\
\text { Positorn: }\end{array}$ & $\begin{array}{l}\text { Sequence Mask: None } \\
\text { Numbeing Mask: None }\end{array}$ \\
\hline
\end{tabular}

f I D I $\bar{D}$ 自 GD +

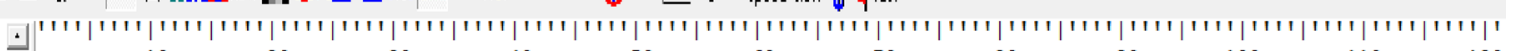
$\begin{array}{rlllllllllll}. & 10 & 20 & 30 & 40 & 50 & 60 & 70 & 80 & 90 & 100 & 110\end{array}$

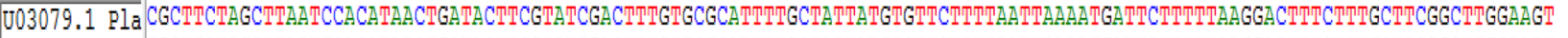

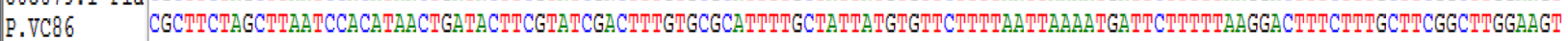

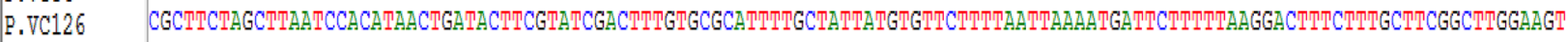

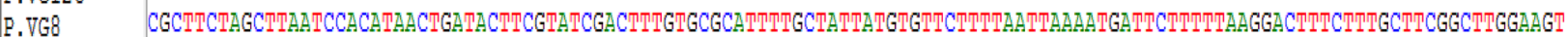

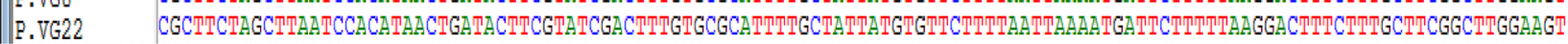

Fig. 3 Multiple sequence alignment of $P$. vivax isolates after clean-up and trimming with its Sal -1 reference sequence 


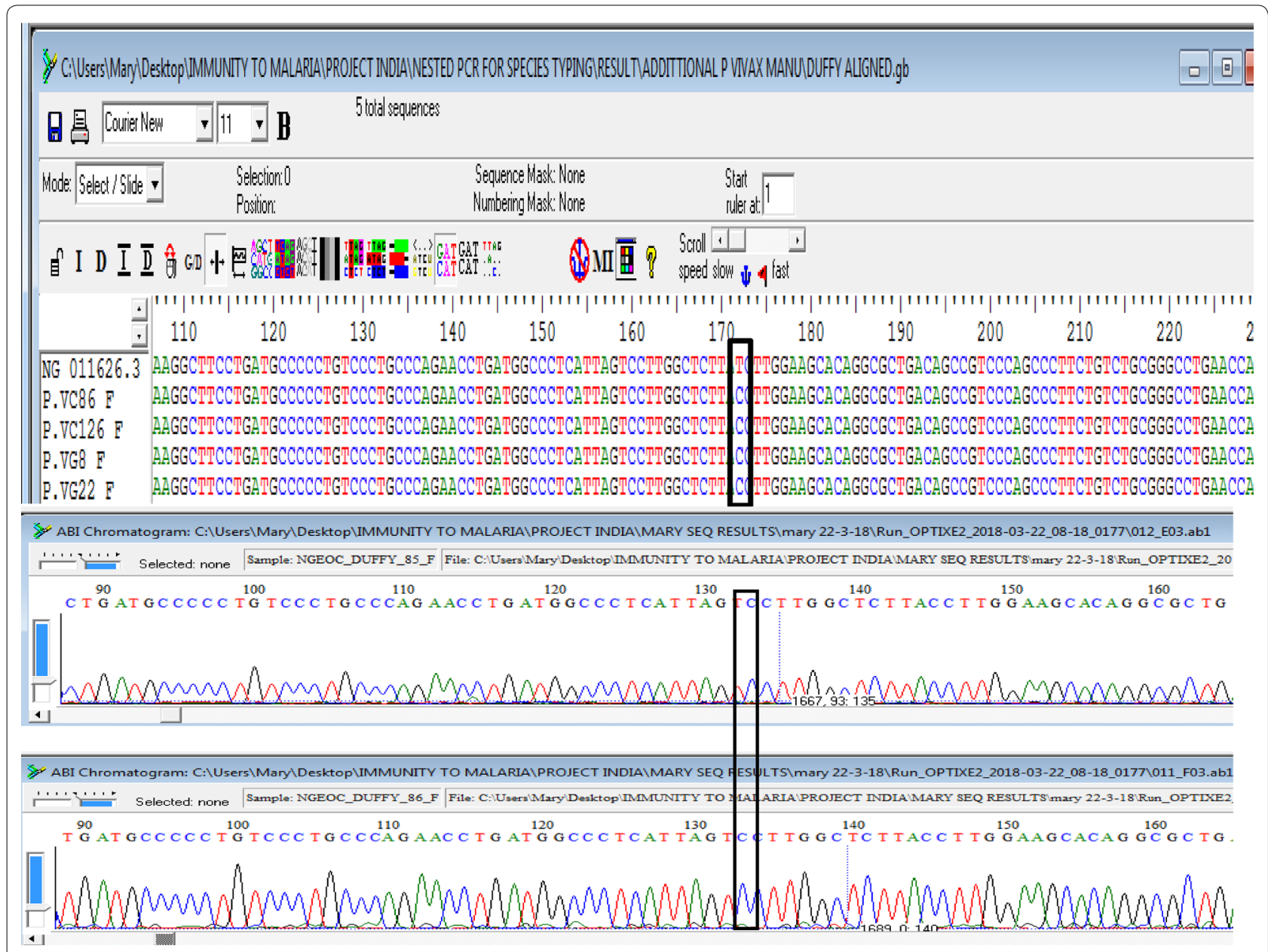

Fig. 4 Multiple sequence alignment of the Duffy gene of the vivax samples displaying the-T33C nucleotide change which validates their Duffy negative status

growing evidence of the proposed gradual incursion of $P$. vivax into sSA sub-region.

Although this study is limited in its samples size and location, the results give support on the need to re-evaluate the spread of $P$. vivax in sSA. Therefore, it is pertinent to carry out more genetic-epidemiological studies in other areas (for example this study covers only two states out of the thirty-six in Nigeria) of the country as with other sSA countries. This will aid in placing appropriate control strategies to combat the menace of malaria infection in this most affected population and may prevent further spread of $P$. vivax in Africa.

\section{Abbreviations}

SSA: sub-Saharan Africa; PCR: Polymerase Chain Reaction; DARC: Duffy Antigen Receptor for Chemokines; RBC: Red blood cell; G6PD: Glucose-6-Phosphate Dehydrogenase Deficiency; TRR: Terminator ready reaction mix; RDT: Rapid diagnostic test; PPV: Positive predictive value; NPV: Negative predictive value.

\section{Acknowledgements}

We thank all the study participants for consenting to donate blood samples for this study. Thanks are also due to the Rector of the Université Cheikh Anta Diop de Dakar, Senegal and Director of ICMR-National Institute of Research in Tribal Health (NIRTH) for providing instrumental facilities. We thank Mrs. Ayanlere, Central Hospital, Nigeria, and Mr. Agbayewa, Ikate Primary Health Care, Nigeria for helping in the collection of samples and Mr. Sri Krishna and Ms. Priyanka Patel, ICMR-NIRTH, India for assistance in the laboratory.

\section{Authors' contributions}

MAO and AD conceptualised and designed the study. MAO, NZ and PKB carried out laboratory analysis. MAO analysed data. MAO and AD wrote manuscript with inputs from the other authors. All authors read and approved the final manuscript.

\section{Funding}

This work was graciously funded by the Department of Science and Technology, and Ministry of External Affairs (MEA), Government of India (Gol), and the Federation of Indian Chambers of Commerce and Industry (FICCI) for awarding the Visiting Fellowship under the CV Raman Fellowship scheme.

\section{Availability of data and materials}

The datasets supporting the conclusion of this article is available in Genbank (MT515456-MT515459 and MT550678-MT550681). All other data can be made available on request to the authors 


\section{Ethical approval and consent for participate}

Approval (IRB/16/347) for this study was obtained from the Institutional Review Board of the Nigerian Institute of Medical research.

\section{Consent for publication}

Not applicable.

\section{Competing interests}

The authors declare that they have no competing interests.

\section{Author details}

${ }^{1}$ Medical Research Council Unit The Gambia at LSHTM, Fajara, P.O. Box 273, Banjul, Gambia. ${ }^{2}$ School of Earth and Environmental Sciences, University of Manchester, Manchester, UK. ${ }^{3}$ Genomic Epidemiology Laboratory, Division of Vector Borne Diseases, ICMR-National Institute of Research in Tribal Health, Jabalpur, India. ${ }^{4}$ Parasitology and Mycology Laboratory, Université Cheikh Anta Diop, Dakar, Senegal. ${ }^{5}$ National Institute of Research in Tribal Health, Jabalpur, Madhya Pradesh 482003, India.

\section{Received: 6 April 2020 Accepted: 17 June 2020}

Published online: 26 June 2020

\section{References}

1. WHO. World malaria report. Geneva: World Health Organization; 2018.

2. Daniels RF, Deme AB, Gomis JF, Dieye B, Durfee K, Thwing Jl, et al. Evidence of non-Plasmodium falciparum malaria infection in Kédougou, Sénégal. Malar J. 2017;16:9.

3. Mbenda HGN, Das A. Molecular evidence of Plasmodium vivax mono and mixed malaria parasite infections in duffy-negative native cameroonians. PLOS ONE. 2014;9:e103262.

4. Fru-Cho J, Bumah VV, Safeukui I, Nkuo-Akenji T, Titanji VPK, Haldar K. Molecular typing reveals substantial Plasmodium vivax infection in asymptomatic adults in a rural area of Cameroon. Malar J. 2014;13:170.

5. Niang M, Diop F, Niang O, Sadio BD, Sow A, Faye O, et al. Unexpected high circulation of Plasmodium vivax in asymptomatic children from Kédougou, southeastern Senegal. Malar J. 2017;16:497.

6. Oboh MA, Badiane AS, Ntadom G, Ndiaye YD, Diongue K. Molecular identification of Plasmodium species responsible for malaria reveals Plasmodium vivax isolates in Duffy negative individuals from southwestern Nigeria. Malar J. 2018;17:439.

7. Gupta B, Gupta P, Sharma A, Singh V, Dash AP, Das A. High proportion of mixed-species Plasmodium infections in India revealed by PCR diagnostic assay. Trop Med Int Health. 2010;15:819-24.

8. Steenkeste N, Rogers WO, Okell L, Jeanne I, Incardona S, Duval L, et al. Sub-microscopic malaria cases and mixed malaria infection in a remote area of high malaria endemicity in Rattanakiri province, Cambodia: implication for malaria elimination. Malar J. 2010;9:108.

9. Trouvay M, Palazon G, Berger F, Volney B, Blanchet D, Faway E, et al. High performance of histidine-rich protein 2 based rapid diagnostic tests in French Guiana are explained by the absence of pfhrp2 gene deletion in $P$. falciparum. PLoS One. 2013;8:e74269.

10. Genton B, D'Acremont V, Rare L, Baea K, Reeder JC, Alpers MP, et al. Plasmodium vivax and mixed infections are associated with severe malaria in children: a prospective cohort study from Papua New Guinea. PLoS Med. 2008:5:e127.

11. Khaireh BA, Briolant S, Pascual A, Mokrane M, Machault V, Travaill C, et al. Plasmodium vivax and Plasmodium falciparum in the Republic of Djobouti: evaluation of their prevalence and potential determinants. Malar J. 2012;11:395.

12. Roggelin L, Tappe D, Noack B, Addo MM, Tannich E, Rothe C. Sharp increase of imported Plasmodium vivax malaria seen in migrants from Eritrea in Hamburg, Germany. Malar J. 2016;15:325.

13. Smoak BL, DeFraites RF, Magill AJ, Kain KC, Wellde BT. Plasmodium vivax infections in U.S. Army troops: failure of primaquine to prevent relapse in studies from Somalia. Am J Trop Med Hyg. 1997;56:231-4.

14. Heppner DG, Magill AJ, Gasser RA, Oster CN. The threat of Infectious diseases in Somalia. N Engl J Med. 1993;328:1061-8.
15. Mekonnen SK, Aseffa A, Medhin G, Berhe N, Velavan TP. Re-evaluation of microscopy confirmed Plasmodium falciparum and Plasmodium vivax malaria by nested PCR detection in southern Ethiopia. Malar J. 2014;13:48

16. Tadesse FG, Pett H, Baidjoe A, Lanke K, Grignard L, Sutherland C, et al. Submicroscopic carriage of Plasmodium falciparum and Plasmodium vivax in a low endemic area in Ethiopia where no parasitaemia was detected by microscopy or rapid diagnostic test. Malar J. 2015;14:303.

17. Seyoum D, Yewhalaw D, Duchateau L, Brandt P, Rosas-Aguirre A, Speybroeck N. Household level spatio-temporal analysis of Plasmodium falciparum and Plasmodium vivax malaria in Ethiopia. Parasit Vectors. 2017;10:196.

18. Nigatu W, Abebe M, Dejene A. Plasmodium vivax and P. falciparum epidemiology in Gambella, south-west Ethiopia. Trop Med Parasitol. 1992:43:181-5.

19. Mahgoub H, Gasim GI, Musa IR, Adam I. Severe Plasmodium vivax malaria among sudanese children at New Halfa Hospital, Eastern Sudan. Parasit Vectors. 2012;5:154

20. Abdelraheem MH, Albsheer MMA, Mohamed HS, Amin M, Hamid MMA Transmission of Plasmodium vivax in Duffy-negative individuals in central Sudan. Trans R Soc Trop Med Hyg. 2016;110:258-60.

21. Culleton R, Carter R. African Plasmodium vivax: distribution and origins. Int J Parasitol. 2012:42:1091-7.

22. Loy DE, Plenderleith LJ, Sundararaman SA, Liu W, Gruszczyk J, Chen Y-J, et al. Evolutionary history of human Plasmodium vivax revealed by genome-wide analyses of related ape parasites. Proc Natl Acad Sci USA. 2018;115:E8450-9.

23. Miller LH, Mason SJ, Clyde DF, McGinniss MH. The resistance factor to Plasmodium vivax in blacks. N Engl J Med. 1976;295:302-4.

24. de Carvalho GB, de Carvalho GB. Duffy blood group system and the malaria adaptation process in humans. Rev Bras Hematol Hemother. 2011;33:55-64.

25. Tournamille C, Colin Y, Cartron JP, LeVan Kim C. Disruption of a GATA motif in the Duffy gene promoter abolishes erythroid gene expression in Duffynegative individuals. Nat Genet. 1995;10:196-201.

26. Reid ME, Lomas-Francis $C$. The blood group antigen Factbook. Cambridge: Elsevier Academic Press; 2004.

27. Ménard D, Barnadas C, Bouchier C, Henry-halldin C, Gray LR. Plasmodium vivax clinical malaria is commonly observed in Duffy-negative Malagasy people. Proc Natl Acad Sci USA. 2010;107:5967-71.

28. Mendes C, Dias F, Figueiredo J, Mora VG, Cano J, de Sousa B, et al. Duffy negative antigen is no longer a barrier to Plasmodium vivax - molecular evidences from the African West Coast (Angola and Equatorial Guinea). PLoS Negl Trop Dis. 2011;5:e1192.

29. Niangaly A, Gunalan K, Ouattara A, Coulibaly D, Juliana MS, Adams $M$, et al. Plasmodium vivax infections over 3 years in Duffy blood group Negative Malians in Bandiagara, Mali. Am J Trop Med Hyg. 2017:97:744-52.

30. Ryan JR, Stoute JA, Amon J, Dunton RF, Mtalib R, Koros J, et al. Evidence for transmission of Plasmodium vivax among a Duffy antigen negative population in Western Kenya. Am J Trop Med Hyg. 2006;75:575-81.

31. Culleton R, Ndounga M, Zeyrek FY, Coban C, Casimiro PN, Takeo S, et al. Evidence for the Transmission of Plasmodium vivax in the Republic of the Congo, West Central Africa. J Infect Dis. 2009;200:1465-9.

32. Guerra-neira A, Rubio JM, Royo JR, Ortega JC, Auñón AS, Diaz PB, et al. Plasmodium diversity in non-malaria individuals from the Bioko Island in Equatorial Guinea (West Central-Africa). Int J Health Geogr. 2006;5:27.

33. Niang M, Thiam LG, Sow A, Loucoubar C, Bob NS, Diop F, et al. A molecular survey of acute febrile illnesses reveals Plasmodium vivax infections in Kedougou, southeastern Senegal. Malar J. 2015;14:281.

34. FMoH. National Malaria Indicator Survey. 2015.

35. Graffeo R, Masucci L, Bugli F, Damiano F, Pinnetti C, Federico G, et al. Multiple malaria infection in a pregnant woman from Nigeria: detection by multiplex PCR. New Microbiol. 2008;31:565-7.

36. Babamale OA, Ugbomoiko U. Status of malaria infection in peri-urban community of north central region of Nigeria. J Bacteriol Parasitol. 2016;7:1-6.

37. Erhabor O, Babatunde S, Uko KE. Some haematological parameters in plasmodial parasitized HIV-infected Nigerians. Niger J Med. 2006;15:52-5.

38. Snounou G, Viriyakosol S, Zhu P, Jarra W, Pinheiro L, DO Rosario V, et al. High sensitivity of detection of human malaria parasites by the use of 
nested polymerase chain reaction higher sensitivity of detection of these four Plasmodium. Mol Biochem Parasitol. 1993;61:315-20.

39. Lo E, Yewhalaw D, Zhong D, Zemene E, Degefa T, Tushune K, et al. Molecular epidemiology of Plasmodium vivax and Plasmodium falciparum malaria among duffy-positive and Duffy-negative populations in Ethiopia. Malar J. 2015;14:84.

40. Mathews HM, Armstrong JC. Duffy blood types and vivax malaria in Ethiopia. Am J Trop Med Hyg. 1981;30:299-303.

41. Poirier P, Doderer-Lang C, Atchade PS, Lemoine J-P, de I'Isle M-LC, Aboubacar A, et al. The hide and seek of Plasmodium vivax in West Africa: report from a large-scale study in Beninese asymptomatic subjects. Malar J. 2016;15:570.

42. Bernabeu M, Gomez-Perez GP, Sissoko S, Niambélé MB, Haibala AA, Sanz A, et al. Plasmodium vivax malaria in Mali: a study from three different regions. Malar J. 2012;11:405.

43. Salem M, Ahmedou O, Lekweiry KM, Deida JM, Emouh AO, Weddady MO, et al. Increasing prevalence of Plasmodium vivax among febrile patients in Nouakchott, Mauritania. Am J Trop Med Hyg. 2015;92:537-40.

44. Ba H, Duffy CW, Ahouidi AD, Deh YB, Diallo MY, Tandia A, et al. Widespread distribution of Plasmodium vivax malaria in Mauritania on the interface of the Maghreb and West Africa. Malar J. 2016;15:80.
45. Chittoria A, Mohanty S, Jaiswal YK, Das A. Natural selection mediated association of the Duffy (FY) gene polymorphisms with Plasmodium vivax malaria in India. PLoS ONE. 2012;7:e45219.

46. Gruszczyk J, Kanjee U, Chan LJ, Menant S, Malleret B, Lim NTY, et al. Transferrin receptor 1 is a reticulocyte-specific receptor for Plasmodium vivax. Science. 2018;359:48-55.

47. Imwong M, Sudimack D, Pukrittayakamee S, Osorio L, Carlton JM, Day NPJ, et al. Microsatellite variation, repeat array length, and population history of Plasmodium vivax. Mol Biol Evol. 2006;23:1016-8.

48. Dalgleish T, Williams JMG, Golden A-MJ, Perkins N, Barrett LF, Barnard PJ, et al. Dsitribution of blood groups in the east African Somali population. J Exp Psychol Gen. 2007;136:23-42.

\section{Publisher's Note}

Springer Nature remains neutral with regard to jurisdictional claims in published maps and institutional affiliations.
Ready to submit your research? Choose BMC and benefit from:

- fast, convenient online submission

- thorough peer review by experienced researchers in your field

- rapid publication on acceptance

- support for research data, including large and complex data types

- gold Open Access which fosters wider collaboration and increased citations

- maximum visibility for your research: over 100M website views per year

At BMC, research is always in progress.

Learn more biomedcentral.com/submissions 